\title{
Ecology and field biology of the sorghum chafer, Pachnoda interrupta (Olivier) (Coleoptera: Scarabaeidae) in Ethiopia
}

\author{
Asmare Dejen $^{1^{*}}$, Yeshitila Merene ${ }^{2}$ \\ ${ }^{1}$ College of Agriculture, Wollo University, Dessie, Ethiopia; *Corresponding Author: Asmare_dj@fastmail.fm \\ ${ }^{2}$ Amhara Regional Agricultural Research Institute, Bahir Dar, Ethiopia
}

Received 25 June 2013; revised 23 August 2013; accepted 5 September 2013

Copyright (C) 2014 Asmare Dejen, Yeshitila Merene. This is an open access article distributed under the Creative Commons Attribution License, which permits unrestricted use, distribution, and reproduction in any medium, provided the original work is properly cited. In accordance of the Creative Commons Attribution License all Copyrights (C) 2014 are reserved for SCIRP and the owner of the intellectual property Asmare Dejen, Yeshitila Merene. All Copyright (C) 2014 are guarded by law and by SCIRP as a guardian.

\section{ABSTRACT}

Studies on sorghum chafer (Pachnoda interrupta) were conducted under field condition for two consecutive years (2005 to 2006) to determine the biology and ecology of the beetle. Average oviposition rate by a single female was $\mathbf{1 . 2 8}$ eggs per day for a period of $\mathbf{1 1}$ days. In general, eggs hatched within 4 to 22 days with a mean of 15.7 days, after which larval and pupal stages lasted a mean of $\mathbf{5 9 . 8}$ and $\mathbf{1 8 . 3}$ days, respectively. The highest rate of oviposition was recorded during the first four days after mating and none after the eleventh day. A total of 156 and 236 sites or samples were investigated from nine habitats (under tree in forest, under tree in crop fields, in a crop fields, border of crop fields, grazing land, riverside, manure heaps, termite mound and cattle dung in homestead) to identify breeding and hibernating areas of the beetles. Fertile humus and moist light soil under the shade of various tree species in the forest and along the riverside were found to be the potential breeding and hibernating areas of the beetles. Metal boards were used and arranged to east wards, where the sources of flights were expected. During June 2005 outbreak, a total of 1770 beetles with equal sex proportion were caught within 15 days from 36 passive metal board traps, with the beetles' infestation being first recorded near the Afar border. Monitoring of flight direction at the time of the outbreak using these metal board traps showed no significant difference in beetle catches among different directions (north, south, east and west). In con- clusion, the beetles could breed in areas where the previous outbreak did not occur; importantly, the beetle hibernated in fertile and moist soils near river bed of all areas of outbreak.

\section{KEYWORDS}

Oviposition; Hibernate; Life Cycle; Flight Direction

\section{INTRODUCTION}

Pachnoda interrupta (Olivier) (Coleoptera: Scarabaeidae: Cetoniinae) is a polyphagous pest distributed particularly in Africa [1]. In Ethiopia, surveys conducted about 20 years ago revealed the presence of nine species of Pachnoda; one was represented by two subspecies [2]. Except for two species, $P$. stehelini Sch. and P. abyssinica Blan. which were often observed above 2000 masl, the remaining species were mainly found in the Acacia woodlands distributed between 800 - 1800 meter above sea level [2].

Among the nine species in Ethiopia, the sorghum chafer, Pachnoda interrupta, has become a well-established regular pest in the last eight years attacking a wide range of crops (over 35 types) and sorghum is the major one $[3,4]$. According to the local farmers, although $P$. interrupta was recognized three decades ago, it damaged sorghum only sporadically [3]. However, between 1993 and 2005, $P$. interrupta has been noted to increase both in density and geographic distribution. The area infested has increased from 1375 ha in 1993 to over 112,000 ha in 2001 [5].

Successful management of $P$. interrupta requires a detailed knowledge of its biology and ecology. Its biology 
was described under laboratory conditions by [6]. Some aspects of the life cycle of $P$. interrupta have described by [2]. In Mali, [1] has also briefly described some aspects of the life history and feeding habits of $P$. interrupta and estimated the yield loss using caged experiments in pearl millet fields. The present study was conducted in the field to elucidate developmental durations of immature stages, adult emergence, and to identify the breeding and hiding areas and source of infestation of the adult beetles in northeastern Ethiopia.

\section{MATERIALS AND METHODS}

\subsection{Oviposition}

Previous studies revealed that the hibernating beetles appearing in every June was mating purpose [3]. Sexually mature and mated females of $P$. interrupta were collected from Sefiberet $\left(09^{\circ} 5474 " \mathrm{~N}, 040^{\circ} 0309 " \mathrm{E}\right)$ and placed in plastic cages in June of 2005 and 2006. Holes were made underside of each pots to avoid water saturation. Three pots per cage were half filled $(10 \mathrm{~cm}$ depth) with moist soil rich in compost and maintained in the field to simulate the beetles' breeding grounds. This was done at Shewarobit (two sites) and Sefiberet using three pots in each location, one cage per location. Five female beetles were kept in each experimental pot and all eggs were collected and removed daily by brushing them gently onto a tray, until they stopped egg laying. Finally the mean number of eggs lay per female per day and the numbers of days for egg laying were calculated. One way analysis of variance was employed.

\subsection{Duration of Developmental Stages (Life Cycle)}

To study the duration of the different developmental stages of sorghum chafer under field conditions, pots were filled with soil brought from the actual breeding area of the beetles and 10 newly laid eggs were placed on each pot and buried in the soil under trees at Shewarobit and Sefiberet. Each of the pots was covered with mesh cloth. Data on duration of each developmental stage was recorded by disturbing through digging the pot every day, every three days and every six days to see the effect of disturbance. A total of nine pots, three for each sampling method were used. Undisturbed pots were included for comparison purpose.

\subsection{Identification of Breeding and Hibernating Areas}

To determine breeding and hibernating areas of Pachnoda interrupta, 236 and 156 plots were investigated, respectively, from nine suspected habitats during February 2005 and August 2006 in areas bordering Afar, Amhara and Oromia regions (Figure 1). Soils from each plot

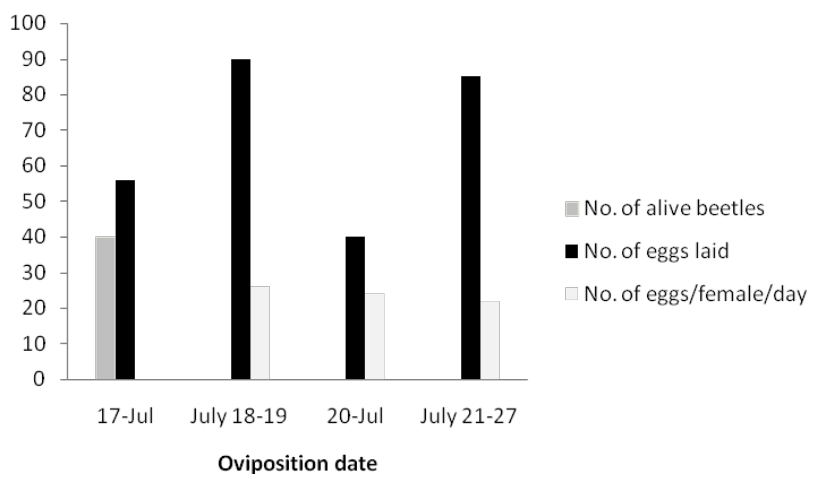

Figure 1. Oviposition rate of sorghum chafer under field condition in Shewrobit.

were investigated for presence of the different growth stages of the insect. Data on number of larvae per meter square, and quiescent adult (F:M) ratio on plots of 0.25 $\mathrm{m}^{2}$ were recorded at a depth of $50 \mathrm{~cm}$. After this depth, beetles were not recorded. Moreover, soil and atmospheric temperature, altitude and surrounding tree species were recorded.

\subsection{Flight Direction}

Flight direction was monitored using 36 passive and reflecting white metal board $(60 \mathrm{~cm} \times 50 \mathrm{~cm})$ traps which were installed to face four directions at $3 \mathrm{~m}$ heights and $100 \mathrm{~m}$ apart from each other in one site. The traps were installed parallel to side of each other. It was replicated in three districts (Kewet, Bati and Habru). At each district three sites were selected starting at the nearest accessible area bordering the Afar region and at five kilometers interval to the west. Data on the number of beetles caught at each trap (metal board) were collected daily starting from the first day of infestation during the adult flight period in early June and continuously for about 15 days and the data were subjected to statistical analysis using general linear model (GLM) of SPSS software.

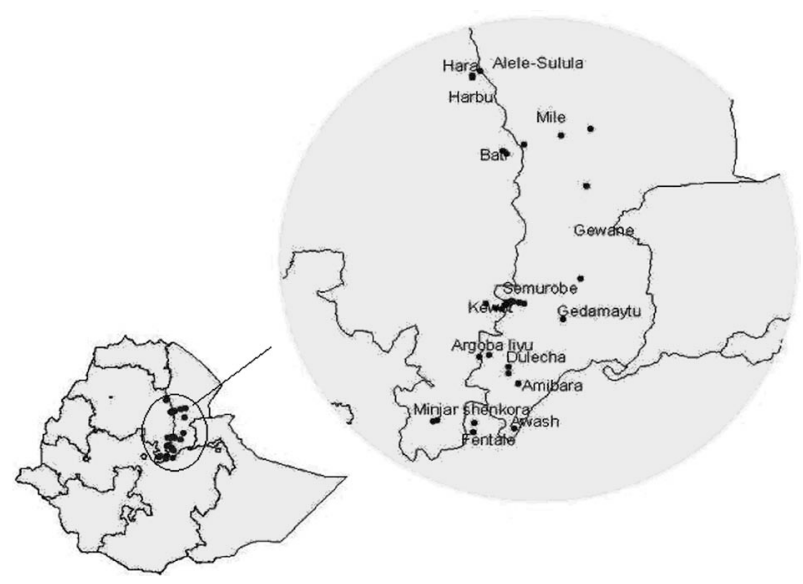

Surveyed areas for identification of the beetles breeding and hibernating habitats. 


\section{RESULTS AND DISCUSSION}

\subsection{Oviposition}

A total of 283 eggs were collected from 45 female beetles, which were used to determine the oviposition rate. Under field conditions, newly emerged beetles in September became sexually mature in June. The females oviposit their eggs singly in the soil. Mean oviposition rate of single females was 1.28 eggs per day for 11 days (Figure 1). This was contrary to the greater number of eggs reported by previous findings under laboratory conditions. An average oviposition rate of 1.8 eggs per female per day over two months was reported by [6]. It reported an oviposition rate of 0.58 eggs per female per day over 25 days [7]. From a study conducted in Mali, [1] reported an oviposition rate of 24 eggs per female per day. This inconsistency in results is attributed to the variation in food provided for the sexually matured insects, soil type and moisture level, and methodologies adopted in egg collection. Moreover, these findings were obtained from laboratory experiments, while our result was from a field study representing real breeding conditions. The diet of the beetles and constant disturbance of egg laying adults had been suggested to determine egg development and rate of oviposition [8]. The beetles were fed banana and freshly cut Acacia flowers and eggs were collected every five days, while [3] provided only banana and eggs were collected every two days [6].

\subsection{Life Cycle}

Pachnoda interrupta is univoltine insect having only one generation per year. In this study the duration of developmental stages was found to be affected by distur- bance made for observation. The life cycle was short in more frequently disturbed treatments. Eggs hatched within 14.1, 17 and 16 days and egg to adult developmental stages took 88.6, 99.5 and 93.5 days when they were observed at every day, 3-day and 6-day intervals respectively and life cycle took 110 days on undisturbed treatments. The overall hatching period for eggs was from 4 to 22 days interval with a mean of 15.7 days. The duration of adult emergence varied from 70 to 114 days and a mean of 93.8 days (Table 1). Under field condition adults died soon after egg laying and this was supported by [2]. In contrast [6] reported that adults survived for six months after egg laying and this might be due to a continuous food supply.

\subsection{The Beetles' Hibernating Habitat}

Adult beetles that emerge in September fly and actively feed on various hosts up to December. Then they disappear and remain quiescent for about six months up to the first rains in June or July to escape the dry season food shortage. Results of our field surveys conducted in Afar and Amhara regions revealed that preferred habitats for hibernating beetles were fertile and moist soils in the forest and river sides shaded by dense branches of different species of trees and shrubs and at a soil depth ranging from 5 to $43 \mathrm{~cm}$ depending on moisture status and vegetation cover (Table 2). The higher the soil moisture, the shallower the beetles dug. In all the surveyed areas, the beetles were not found in dry and sun exposed soils. In most cases, the quiescent beetles were found in altitudes ranging from 700 to 1660 meters above sea level and at soil temperatures varying from $22^{\circ} \mathrm{C}$ to $25^{\circ} \mathrm{C}$ (Table 3).

Table 1. Period of time elapsed (in days) in different developmental stages of sorghum chafer as disturbed every day, three days and six days for data collection.

\begin{tabular}{|c|c|c|c|c|c|c|c|c|c|}
\hline \multirow[t]{2}{*}{ Stages (days) } & \multicolumn{2}{|c|}{ Daily disturbed } & \multicolumn{2}{|c|}{ Disturbed every three days } & \multicolumn{2}{|c|}{ Disturbed every six days } & \multirow[t]{2}{*}{ Undisturbed } & \multicolumn{2}{|c|}{ Overall } \\
\hline & Range & Mean & Range & Mean & Range & Mean & & Range & Mean \\
\hline Egg & $8-20$ & 14.1 & $5-21$ & 17 & $4-22$ & 16 & - & $4-22$ & 15.68 \\
\hline Larvae & $55-67$ & 61 & $59-66$ & 62.5 & $53-59$ & 56 & - & $53-67$ & 59.83 \\
\hline Pupa & $13-14$ & 13.5 & $17-23$ & 20 & $18-25$ & 21.5 & - & $13-25$ & 18.33 \\
\hline Egg-Adult & $76-101$ & 88.6 & $81-110$ & 99.5 & $75-106$ & 93.5 & 110 & $70-114$ & 93.8 \\
\hline
\end{tabular}

Tab le 2. Total number of samples, number of samples with larvae and adult in suspected breeding and hibernating areas.

\begin{tabular}{|c|c|c|c|c|c|}
\hline \multirow{2}{*}{$\begin{array}{l}\text { Suspected breeding } \\
\text { and hibernating habitats }\end{array}$} & \multicolumn{3}{|c|}{ Hibernating area } & \multicolumn{2}{|c|}{ Breeding area } \\
\hline & $\begin{array}{l}\text { Total number } \\
\text { of samples }\end{array}$ & $\begin{array}{l}\text { Number of samples with } \\
\text { quiescent adult beetles }\end{array}$ & $\begin{array}{l}\text { Soil depth } \\
\text { (cm) }\end{array}$ & $\begin{array}{c}\text { Total number } \\
\text { of samples }\end{array}$ & $\begin{array}{c}\text { Samples with larvae } \\
\text { of sorghum chafer }\end{array}$ \\
\hline Under trees in the forest & 45 & 38 & $5-20$ & 116 & 70 \\
\hline Under tree in crop land & 13 & 0 & & 12 & 0 \\
\hline Crop land & 30 & 0 & & 15 & 0 \\
\hline Boarder of crop land & 18 & 0 & & 20 & 0 \\
\hline Pasture land & 11 & 0 & & 27 & 0 \\
\hline Sheep and goat manure heaps & 9 & 0 & & 12 & 0 \\
\hline Termite mound & 6 & 0 & & 15 & 0 \\
\hline Cattle dung in homestead & 8 & 0 & & 6 & 0 \\
\hline
\end{tabular}


Tab le 3. Quiescent adult beetles of Pachnoda interapta in $0.25 \mathrm{~m}^{2}$ plots, and the soil and atmospheric temperatures and altitude range of sampled areas.

\begin{tabular}{|c|c|c|c|c|c|c|}
\hline \multirow{2}{*}{ District } & \multicolumn{3}{|c|}{ Number of beetles $/ 0.25 \mathrm{~m}^{2}$} & \multicolumn{2}{|c|}{ Temperature $\left({ }^{\circ} \mathrm{C}\right)$} & \multirow{2}{*}{ Altitude ranges (m.a.s.l) } \\
\hline & Female & Male & Total & Soil & Atmospheric & \\
\hline \multicolumn{7}{|c|}{ Amhara region } \\
\hline Harbu & 4 & 5 & 9 & 22 & 28 & $1150-1400$ \\
\hline Bati & 2 & 2 & 4 & 24 & 28 & $1300-1360$ \\
\hline Kewet & 5 & 5 & 10 & 24 & 29 & $1320-1460$ \\
\hline Minjar & 7 & 8 & 15 & 22 & 31 & $1200-1660$ \\
\hline \multicolumn{7}{|c|}{ Afar region } \\
\hline Semurobe Gelealo & 25 & 22 & 47 & 25 & 33 & $800-1190$ \\
\hline Dulecha & 5 & 7 & 12 & 24 & 34 & $700-990$ \\
\hline Argoba Liyu & 8 & 6 & 14 & 22 & 29 & $1050-1260$ \\
\hline
\end{tabular}

The dominant tree species under which the beetles were hibernating were different from Acacia species, Ximentia americana (Enkoy), Zizyphus spinacristy (Qurqura), Capparis tomentosa (Gumero), Berchemia discolor (Jejeba), Carissa edulis (Agam), Euclea schimperi (Dedeho) and others. Previously, farmers perceived that beetles emerged in September and disappeared to Afar region after heavily damaging the crop. However, the beetles could hibernate in all invaded areas or regions as far as favorable hibernating habitats exist (Table 3).

\subsection{The Beetles' Breeding Habitat}

Once male and female beetles sexually matured, the quiescent beetles emerged from their hibernating habitats starting from the first rain shower in June, then mating, oviposition and other developmental stages to the second generation continued. A total of 236 samples of one meter square areas were taken from all the suspected breeding habitats. Eggs and larvae of sorghum chafer beetles were obtained only from 70 of the 116 samples in soils and litters under trees in the forest and 5 of the 13 soil samples taken from under trees in river sides (Table 2). Beetle preferred moist and light soils in forest and river sides under shade of acacia and other tree species for reproduction (Table 2). It was suggested that goat and sheep dung piles were the potential breeding habitats of the pest [2]. In the Afar region, heaps of goat and sheep dung were considered as breeding places of sorghum chafer and control strategies focused on spreading and burning of the piles of dung. This finding, however, did not find the suspected habitats, such as under trees in crop field, on crop field, boarder of crop field, pastureland, sheep and got manure heaps, termite mound and cattle dung in homestead important for reproduction of the beetles.

Larvae were found from breeding habitats in the Amhara, Afar and Oromia regions at a depth of $2-3 \mathrm{~cm}$ and soil and atmospheric temperatures of $22.5^{\circ} \mathrm{C}-31.5^{\circ} \mathrm{C}$ and $25.5^{\circ} \mathrm{C}-34^{\circ} \mathrm{C}$, respectively (Table 4). The beetle larvae were found in altitudes ranging from 519 to 1475 meters above sea level. Although larvae were found in surveyed areas in Afar, Amhara and Oromia regions, the maximum and minimum larval density per meter square of 322 and 3 were recorded from the Amibara district of the Afar region and Fentale woreda of East Oromia, respectively (Table 4).

\subsection{The Beetles' Flight Direction during Out Breaks}

From all 36 metal boards, a total of 1770 beetles (852 males \& 918 females) were caught within 15 days. The ratio of male and female beetles during this period was one to one. Monitoring of the sorghum chafers' flight direction using metal boards during the time of infestation showed that there was no significant difference in number of beetles caught per trap per day between the four directions (Table 5). Surveys using metal traps did not show the source of the infestation at the time of the outbreak. This might be due to the mixed and swarming flight behavior of the beetles after emergence from the soil in search of food and mates. In most cases, the beetle infestation was first recorded in areas near the Afar border (Table 6). This might be because of the low altitude and high temperature in the area that enhanced insect development and infestation.

\section{CONCLUSION AND RECOMMENDATIONS}

The adult beetles that emerged during the day time in September and October were extremely numerous and often caused considerable damage to sorghum, maize and several other host plants until the end of November or to some extent to the beginning of December. At the end of November, the insect began to hide in the hibernating habitat and remained quiescent until it emerged again as a sexually matured adult beetle in June. Moist and composted light soils in the forest and river side heavily shaded by different tree species were the suitable habitats for hibernation and breeding of the beetles. Under field 
Tab le 4. Number of larvae obtained (number $/ \mathrm{m}^{2}$ ) and soil and atmospheric temperatures, soil depth and altitude of the surveyed areas from where the larvae were collected.

\begin{tabular}{|c|c|c|c|c|c|}
\hline \multirow{2}{*}{ District } & \multirow{2}{*}{ Number of larvae per meter square } & \multicolumn{2}{|c|}{ Temperature $\left({ }^{\circ} \mathrm{C}\right)$} & \multirow{2}{*}{ Soil depth } & \multirow{2}{*}{ Altitude ranges m.a.s. } \\
\hline & & Soil & Atmospheric & & \\
\hline \multicolumn{6}{|c|}{ Amhara region } \\
\hline Harbu & 22 & 24.5 & 25.5 & 2 & $1180-1475$ \\
\hline Bati & 12 & 25 & 34 & 2 & $1300-1400$ \\
\hline Kewet & 26 & 22.5 & 31 & 2 & $1360-1441$ \\
\hline \multicolumn{6}{|c|}{ Afar region } \\
\hline Mile & 51 & 29 & 33.5 & 3 & $519-900$ \\
\hline Gewane & 34 & 31.5 & 31 & 3 & $630-690$ \\
\hline Amibara & 322 & 26 & 31 & 3 & $735-750$ \\
\hline Awash & 10 & 25 & 28.5 & 3 & $975-1020$ \\
\hline \multicolumn{6}{|c|}{ Oromia region } \\
\hline Fentale & 3 & 27 & 32 & 3 & $1000-1030$ \\
\hline
\end{tabular}

Table 5. Mean number of beetles caught/day/trap in north, south, west and east directions during June, 2001 outbreak in Kewet, Bati and Harbu districts of the Amhara region.

\begin{tabular}{cccccc}
\hline Direction & Kewet & Bati & Harbu & Mean & Total \\
\hline North & 40.33 & 48.67 & 79.67 & 56.2 & 46.4 \\
South & 50.33 & 56.0 & 33.0 & 30.0 & 185.73 \\
East & 51.33 & 21.67 & 17.0 & 30.67 & 120.0 \\
west & 47.67 & 12.67 & 31.67 & & 122.68 \\
LSD & NS & NS & NS & & \\
CV & $\mathbf{1 8 . 4}$ & $\mathbf{5 3 . 2 2}$ & $\mathbf{6 8 . 3}$ & & \\
\hline
\end{tabular}

Tab le 6. First date of beetle catches using metal boards at different directions and locations during June-July 2006 outbreak.

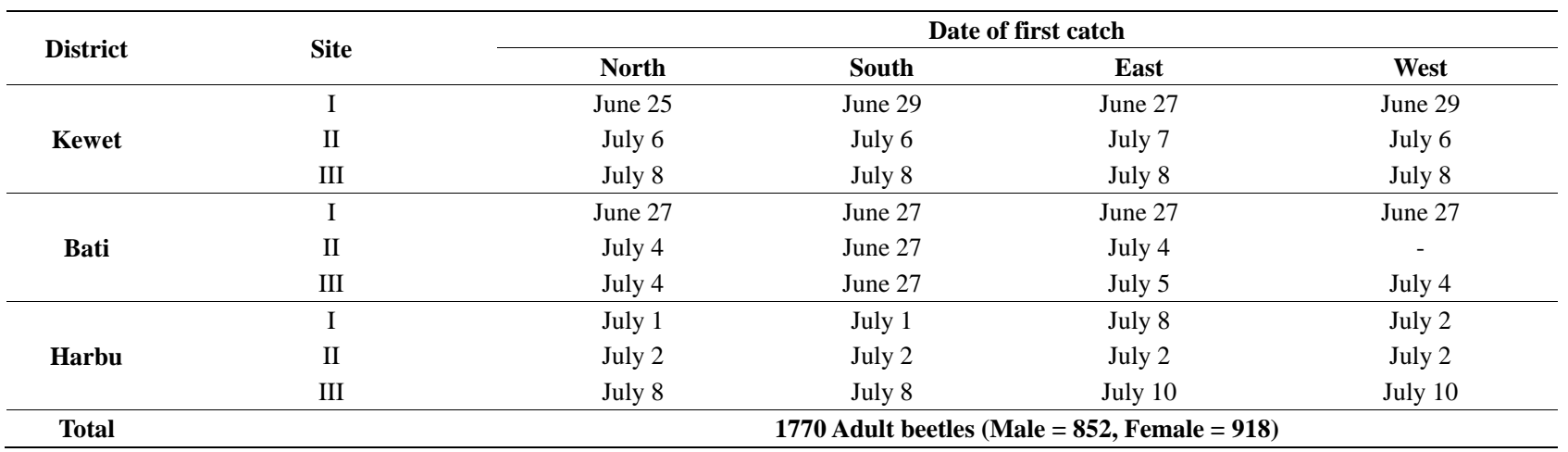

conditions, new beetles that emerged in September became sexually mature in June. Single female beetles after mating oviposited about 1.28 eggs daily for eleven days in the soil and then died. Egg to adult development stages of sorghum chafer under field conditions took on average 93.84 days.

Based on this, we can suggest at which stage of insect development and at what time of the year control should be targeted. Controlling sexually matured quiescent beetles that emerge in June and are ancestor parents of the devastating September beetles should be the first control target. Moreover, control of the newly emerged beetles during September to October should also be continued. Although the larvae could be considered as good targets for control through mechanical destruction, the practical application is difficult due to their inaccessible breeding area (acacia wood land).

\section{REFERENCES}

[1] Grunshaw, J.P. (1992) Field studies on the biology and economic importance of Pachnoda interrupta (Coleoptera: Scarabaeidae) in Mali West Africa. Bulletin of Entomological Research, 82, 19-27.

http://dx.doi.org/10.1017/S0007485300051452

[2] Clark, R.O.S. and Crowe, T.J. (1977) The genus Pachnoda in Ethiopia. Identification, pest status and control of the species. IAR, Addis Ababa.

[3] Hiwot, L., Adane, K., Yeraswork, Y., Legesse, Z., Tsegaye, E., Mohamed, S. and Ararsa, W. (1999) The significance, 
distribution and control of sorghum chafer, Pachnoda interrupta (Oliver) Coleoptera: Scarabaeidae in Amhara and Afar regions. MOA and EARO, Addis Ababa.

[4] Hiwot, L. (2000) Historical background on the pest status and control of sorghum chafer, Pachnoda interrupta (Coleoptera: Scarabaeidae) in Ethiopia. Proceedings of the Workshop on the Development of Monitoring and Control Strategy against Sorghum Chafer, Pachnoda interrupta (Coleoptera: Scarabaeidae) in Ethiopia, MOA, Addis Ababa, 28 February-2 March 2000.

[5] Hiwot, L. (2001) Distribution of sorghum chafer in Ethiopia, control approaches and their limitations. Proceeding of the Workshop on Sorghum Chafer, Pachnoda interrupta (Oliver) (in Amharic), Dessie, 12-14 February 2001, 28.
[6] Seneshaw, A. and Mulugeta, N. (2002) Study on the biology of sorghum chafer, Pachnoda interrupta (Coleoptera: Scarabaeidae) under laboratory condition. Pest Management Journal of Ethiopia, 6, 31-36.

[7] Gebeyehu, M. and Feleke, B. (2002) Study on the effect of physical factors and soil types on the development and food preference of sorghum chafer, Pachnoda interrupta (Oliver) Coleoptera: Scarabaeidae. MSc. Thesis, Addis Ababa University, Addis Ababa.

[8] Donaldson, J.M.I. (1992) Biologies and rearing techniques for twenty-two species of Cetoniinae (Coleoptera: Scarabaeidae). Technical Communication Department of South Africa, 237, 1-22. 